Voix et Images

voixetimages

\title{
Les femmes sont plus fines que les hommes
}

\section{Monique Proulx}

Volume 18, numéro 1 (52), automne 1992

Les écritures masculines

URI : https://id.erudit.org/iderudit/201000ar

DOI : https://doi.org/10.7202/201000ar

Aller au sommaire du numéro

Éditeur(s)

Université du Québec à Montréal

ISSN

0318-9201 (imprimé)

1705-933X (numérique)

Découvrir la revue

Citer cet article

Proulx, M. (1992). Les femmes sont plus fines que les hommes. Voix et Images, 18(1), 73-76. https://doi.org/10.7202/201000ar d'utilisation que vous pouvez consulter en ligne.

https://apropos.erudit.org/fr/usagers/politique-dutilisation/ 


\section{Les femmes sont plus fines que les hommes}

\section{Monique Proulx}

Il sait qu'elle s'appelle Mirella parce que la première fois qu'il l'a vue, elle déverrouillait la porte de son appartement en compagnie d'une fille qui disait: aIl me tue, Mirella $a_{8}$ je te jure, il me tue." Puis, une autre fois, ils se sont croisés dans l'escalier, lui encombré de sacs d'épicerie qui lui montaient jusqu'au menton, elle emcombrée de rien sur ses jambes brunes qui lui montaient jusqu'à la taille, et il l'a saluée en souriant par-dessus les poireaux et les feuilles de radis, mais elle n'a pas dû l'entendre puisqu'elle n'a rien répondu.

Et maintenant, cette fille qui s'appelle Mirella et qui lui plaît est presque nue à côté de lui.

La grille du balcon les sépare, à vrai dire, et sans doute beaucoup d'autres choses, aussi, mais il baigne dans ses émanations d'huile solaire, et s'il levait les yeux de son ordinateur, peut-être serait-il bronzé par les ultraviolets qui la bombardent. Il ne lève pas les yeux de son ordinateur. il ne faut pas regarder. Elle se dépouille peu à peu de son revêtement minimal, la moitié de son soutien-gorge choit tandis qu'elle s'oint d'huile sacrificielle, une fesse entière fait à l'air libre une entrée remarquée, mais il ne faut surtout pas regarder. Les femmes ont le droit de se dévêtir pour elles seules, pour le soleil, pour combattre l'ostéoporose, les femmes n'aiment pas qu'on regarde ce qu'elles exposent au regard. Il est si tendu par l'effort de garder la tête basse et l'œil cataleptique sur l'écran qu'il fait un faux mouvement et renverse le parasol, et il faut bien alors qu'il se penche pour l'attraper et que ses yeux à ce moment soient sur elle, et c'est ce moment précis, très court, unique, qu'elle choisit pour se tourner vers lui et constater qu'il la regarde et le toiser d'un air offensé avant de se draper dans son peignoir et de disparaitre à l'intérieur.

Il s'appelle Thomas, il a trente-neuf ans, et il se remet lentement d'une séparation difficile. Il écrit des scénarios de films qu'il parvient à vendre après des réécritures et des compromis multiples. Il est rompu 
à toutes les sortes de compromis. Le scénario sur lequel il travaille raconte l'histoire d'un transsexuel, un homme qui a choisi de vivre dans la peau d'une femme, ou plutôt un homme persuadé qu'il est une femme que la nature a floué de son corps et qui n'a de cesse de le reconquérir. C'est une histoire complexe et impossible, et il ne sait plus comment il s'en sortira ni pourquoi il y a pénétré. Le soleil descend en flèche sur les arbres du parc, une moiteur se met à flotter dans l'air comme un encens, et il est toujours assis sur le balcon. Il voit des musiciens qui tam-tament près de la statue de la Victoire, il voit un homme qui urine dans un bosquet, une fille longiligne qui danse. Il voit des couples, des enfants et des chiens, et des victuailles que l'on étend sur les tables de pique-nique, il voit tout cela, il voit l'humanité divisée en deux camps adverses et irréductibles, d'un côté les Guerriers qui pissent dans les bosquets, de l'autre les Bacchantes qui dansent au son du tambourin. Comment l'alliance serait-elle possible?

Quand il est dans la cuisine à se fabriquer vite fait une salade, il entend des femmes sur le balcon de Mirella. La voix de celle qui disait: : Il me tue dit maintenant: "Je vous jure, un serin dans un jeu de quilles", et elles rient, elles rient comme des adolescentes, en cascades interminables qui leur arrachent de petites plaintes pointues. L'odeur du joint d'herbe vient lui chatouiller les narines et le replonge tout à coup dans une antiquité brumeuse et agréable, du temps où le bonheur n'était que cela, fumer et rire. Il sort sur le balcon sans chercher de prétexte. Elles sont trois, parmi lesquelles Mirella dans une robe rouge. Quand elles le voient, elles s'interrompent complètement. Il leur dit bonsoir, Mirella répond: Bonsoir, mais pas les deux autres, et soudain elles sont prises d'un fou rire énorme, inextinguible, qui dresse des barricades autour d'elles et lui intime l'ordre de déguerpir chez lui.

Sa femme téléphone, dans la soirée. Son ex-femme, quoiqu'il n'aime pas penser à elle en ces termes. Elle lui pose des questions sommaires sur sa santé, puis elle en arrive au vif du sujet. *Il n'est pas encore rentré, dit-elle. IL, c'est-à-dire Jean, celui pour lequel il y a deux ans elle a jeté beaucoup de choses par-dessus bord, dont Thomas. Sa voix est si basse et déprimée qu'il doit tendre l'oreille pour entendre ce qu'elle dit. "Il n'appelle jamais pour dire qu'il ne rentre pas. Je suis là, comme une dinde, à l'attendre. Moi aussi, je pourrais boire un verre avec des copines, m'asseoir a une terrasse au lieu de l'attendre." Elle soupire, il la voit se balancer près du téléphone, une mèche de cheveux torturée entre ses dents. •Pourquoi il n'appelle pas? dit-elle. C'est tout ce que je lui demande, prévenir 
quand il ne rentre pas. Je ne demande qu'un peu de respect. Est-ce trop demander?... Une femme ne ferait jamais ça. Est-ce qu'une femme t'a déjà fait ça?..." Il ne s'agit visiblement pas d'une question, puisqu'elle ne lui laisse pas le temps de répondre. : C'est sûr, ajoute-telle avec un petit rire amer, ça ne changera jamais, les femmes sont plus fines que les hommes. Comment va ton scénario, dis-moi?... Il entend un bruit, derrière elle. Lorsque sa voix revient, elle est redevenue celle de toujours, animée et chaleureuse. -Le voilà, dit-elle. The fucking bastard. Et elle rit pour vrai, remplie d'un soulagement joyeux. * Mais je t'appelais pour autre chose. Viens manger, samedi. Je fais de l'osso bucco. Tu aimes l'asso bucco. Il dit qu'il ne sait pas, qu'il ne croit pas qu'il pourra.

11 est incapable de travailler, après, submergé par une colère imprécise. Il va sur le balcon. Il voit une robe rouge, appuyée contre la balustrade, mais il choisit de ne pas la voir, de faire comme s'il était seul, le seul être humain sur la terre à contempler les arbres du parc ployer sous les ténèbres. C'est elle qui lui parle. Elle lui demande du feu. Il en a, même s'il ne fume pas. Elle s'allume une cigarette, incendiaire dans sa robe rouge. Et voilà qu'elle lui pose des questions, ce qu'il fait, où il habitait avant, et elle écoute les réponses en regardant devant elle, le front sillonné de petites rides. Ses cheveux sombres dégagent une odeur de caramel, sa bouche sans maquillage est aussi rouge que sa robe, comment résister \$ l'envie de pénétrer plus avant dans l'intimité affolante de cette odeur, de tout ce rouge? Il lui dit qu'il a une bouteille de sauternes sur la glace, il lui offre un verre. Elle le regarde pour la première fois directement en face, avec des yeux piquetés d'étonnantes lueurs mauves, ế elle dit: "Certainement pas."

Il travaille, jusque tard dans la nuit. Cet homme-femme à qui il a donné naissance l'entraîne dans un sinistre labyrinthe où il va et vient, un bandeau sur les yeux, les pieds vacillant sur les incertitudes. Il souhaiterait demeurer au-dessus de la mêlée, manipuler de haut les structures et les personnages comme il a appris à le faire, mais il n'y parvient pas, ce transsexuel l'empoigne de sa main osseuse et le force à atterrir en face de lui, là où les Guerriers et les Bacchantes échangent leurs déguisements et lui arrachent le sien. Quand il parvient à s'endormir, il rêve qu'il enfile une robe rouge et que son père lui dit, avec toute la réprobation dont il était capable: "Le rouge te va très mal, Mirella.:

La journée suivante, le soleil est masqué par une humidité écrasante. Le moindre mouvement arrache au corps des sueurs olympiques. Thomas écrit à l'intérieur, amarré sous les pales du ventilateur, il 
écrit toute la journée en buvant de la bière. Et à cinq heures, lorsque les premiers roulements de l'orage atteignent la montagne, il a terminé.

C'est un orage colossal, qui jette tout dans l'anarchie, qui expédie le monde organisé aux premiers balbutiements de la purée cosmique. Les lumières giclent de partout, le bruit est infernal, l'eau tombe si raide et verticale qu'elle en devient une arme offensive. Il regarde le spectacle, debout sur le balcon. Il sourit. Il la devine dans l'embrasure de sa porte, une tache rouge dans le contre-jour. Elle dit: "C'est terrifiant, toute cette violence. Elle s'avance à sa hauteur et reste là, immobile comme lui, parcourue de tressaillements a chaque fois que le tonnerre éclate. Elle dit: :Je m'excuse pour hier, je suis un peu sauvage." Elle dit encore: "Si l'offre tient toujours, je prendrais bien un verre de sauternes. - Il se tourne à demi vers elle. Elle se tient les bras serrés contre la poitrine, comme font les femmes quand elles ont peur et cherchent un peu de protection. Il se détoume pour contempler l'orage. Il ne répond pas. 